\title{
Physical Strain, Exposure to Noise and Postural Assessment in Motor-Manual Felling of Willow Short Rotation Coppice: Results of a Preliminary Study
}

\author{
Stelian Alexandru Borz, Nicolae Talagai, Marius Cheța, Diana Chiriloiu, Alex Vinicio \\ Gavilanes Montoya, Danny Daniel Castillo Vizuete, Marina Viorela Marcu
}

\begin{abstract}
Biomass for energy production and other bioproducts may be procured from various sources including willow short-rotation coppice (WSRC). Management of WSRCs involves several operations, including harvesting, which accounts for the greatest cost share and, if conducted motor-manually, it can expose the workers to noise, uncomfortable work postures and high cardiovascular loads. In this study, we evaluated the productivity, physical strain, exposure to noise, and postural risk index of workers operating in motor-manual felling of WSRC using a set of automatic dataloggers. Productivity of felling operations was rated at $0.10 \mathrm{ha} / \mathrm{h}$, which is in line with the results reported by other studies. Cardiovascular load was rated at cca. $35 \%$ of the HRR, indicating a medium to heavy work experienced by the feller, with a greater contribution of tasks involving movement. Exposure to noise $\left(L_{E X, 8 h}=95.19\right)$ exceeded the limit value set by the European legislation ( $87 \mathrm{dBA}$ ) and it could increase as a function of the engine utilization rate, which was $68 \%$ in this study, advocating for mandatory wearing of protective equipment. Postural risk index was evaluated at $191.11 \%$ for the worker handling the brush cutter and at 192.02\% for the manual assistant indicating rather reduced risks, but also the need to evaluate how the dynamic work of the upper limbs would affect the workers' health. While this work stands for a preliminary case study, the procedures described may be successfully used to easily collect long-term data in such operations.
\end{abstract}

Keywords: physical strain, exposure to noise, postural risk index, willow, short rotation coppice, sensors, automation.

\section{Introduction}

Biomass for energy production can be procured from various sources including forests, wood processing residues, common agriculture and dedicated tree plantations established on agricultural or marginal lands. Among the dedicated tree plantations, willow short rotation coppice (WSRC) has been intensively tested and used in many European countries because it can provide investment returns on short time (Vanbeveren et al. 2018) and it may help secure the income of farmers (Pecenka et al. 2014).
Improvement of operational management, especially of harvesting operations, can contribute to the success of WSRC since the fully-mechanized harvesting alone accounts for one third to one half of the WSRC production costs (Buchholz and Volk 2011, El Kasmioui and Ceulemans 2013) and for one third of total energy inputs (Eisenbies et al. 2014). Meanwhile, motor-manual harvesting of WSRC still represents an affordable option among small scale farmers (Talagai et al. 2017), who lack the ability to purchase expensive purpose-built equipment (Spinelli et al. 2012) and often decide to carry on their harvests manually 
(Schweier and Becker 2012). While it can return highdelivery costs compared to the dedicated equipment (Vanbeveren et al. 2015), in many cases motor-manual harvesting of WSRC is the solely available option, which in developing countries is also sustained by lower labor costs.

Nevertheless, the sustainability of WSRC motormanual harvesting operations should also consider the compatibility of equipment and operational conditions to the workers undertaking such tasks (Borz et al. 2018, Talagai et al. 2017). To this end, motor-manual felling of WSRCs can be carried out using either a chainsaw (Burger 2010, Schweier and Becker 2012) or a brush cutter (Borz et al. 2018, Guidi et al. 2013, Talagai et al. 2017). While the technical capability of brush cutters is generally aligned to the operational environment as being characteristic to WSRCs, where the diameter and height of the stems are small (Talagai et al. 2017), research carried out in traditional forestry has shown that their operation requires intensive physical work (Toupin et al. 2007). However, the effort undertaken by workers carrying on operations in traditional forestry is often affected by the slope, which could be the greatest contributor to the physical strain (Magagnotti and Spinelli 2012), a fact that is not specific to WSRCs, which are typically established on relatively flat lands. In addition, the operation of tools, such as chainsaws or brush cutters, may expose their operators to risks of musculoskeletal disorders, which depend to a great extent on the operational environment and tasks to be undertaken. In forest operations, for instance, both manual and motor-manual tasks are often characterized by awkward work postures (Corella Justavinio et at. 2015), which increase the risk of musculoskeletal disorders (Calvo 2009, Zanuttini et al. 2005). Furthermore, tools equipped with two-stroke engines, such as those commonly used in motor-manual operations, expose the workers to other harmful factors such as noise (Taoda et al. 1987), which can result in hearing loss (Fonseca et al. 2015, Tunay and Melemez 2008). Therefore, in order to be sustainable, motor-manual harvesting of WSRCs should also be compatible with workers. While the economic and productive performances of WSRC harvesting operations have been extensively researched, including those using motor-manual equipment, the ergonomics of motor-manual harvesting operations of WSRCs have been less studied.

The aim of this study was to examine the physical strain, exposure to noise and the risk of musculoskeletal disorders experienced in motor-manual felling operations of WSRCs. Study objectives were set to:
$\Rightarrow$ evaluating the time consumption and productive performance of motor-manual felling operations implemented in WSRCs as a prerequisite to describe the performed work tasks

$\Rightarrow$ evaluating the physical strain of fellers by measurements of heart rate

$\Rightarrow$ evaluating the exposure to noise of fellers using small dataloggers

$\Rightarrow$ evaluating the postural risk index in motormanual felling operations of WSRCs using the OWAS method.

\section{Materials and Methods}

\subsection{Study Location, Work Organization and Data Collection Procedures}

This study was carried out on $11^{\text {th }}$ March 2017, in a willow short rotation coppice (WSRC) located at $46^{\circ} 04^{\prime} 22^{\prime \prime} \mathrm{N}-\mathrm{E} 26^{\circ} 10^{\prime} 56^{\prime \prime} \mathrm{E}, 600 \mathrm{~m}$ above sea level on a flat land (Fig. 1) near Poian village, Covasna County, Romania. The owner of the WSRC is currently using this plantation to procure regeneration material (cuttings), therefore the WSRC was harvested on smaller plots, typically each two years. All the WSRCs from the area are established using a high-density plantation scheme $(0.75 \mathrm{~m}$ between rows and $1.50 \mathrm{~m}$ between twin rows) resulting in a plant density of cca. 14000 individuals per hectare (Scriba et al. 2012).

In the Romanian WSRC harvesting practice, smallsized stems are usually harvested in several stages (Talagai and Borz 2016), the first one consisting of motor-manual felling. Depending on the plot size, the WSRCs owners may use one or two teams to fell the stems. When using two teams, a safety distance is kept between them (Talagai and Borz 2016).

During the study, a smaller plot having an area of 0.65 ha (Fig. 1) was harvested by a single team consisting

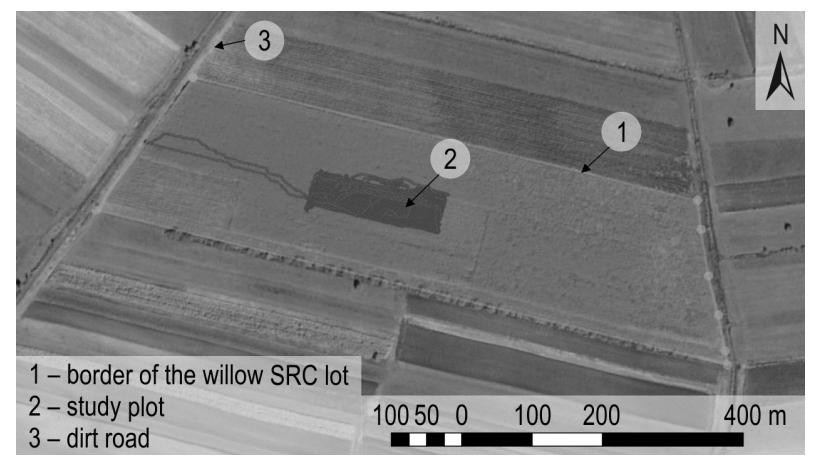

Fig. 1 Study site 


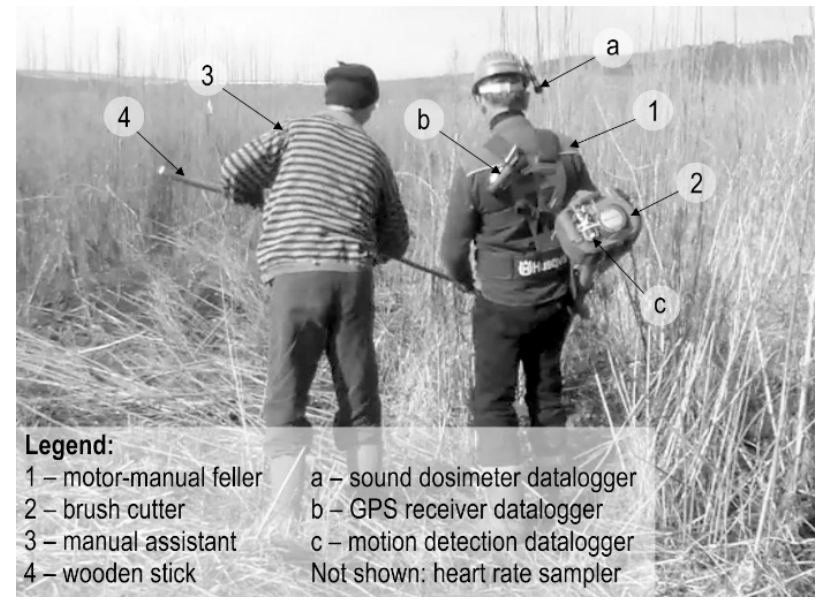

Fig. 2 Work organization and placement of dataloggers

of a motor-manual feller and a manual assistant (Fig. 2). In this kind of configuration (Talagai et al. 2017, Borz et al. 2018) work organization is relatively simple consisting of a work cycle that may be divided into work events such as the advancement on a single row to fell the stems, exits from the felled rows and movements to enter new rows that are usually located at the opposite side of the plot. Nevertheless, previous studies have shown that, in some cases, work teams may operate on smaller patches (Talagai et al. 2017) and that different kinds of delays may occur both in the plot and at the headlands (Borz et al. 2018). Since the practical experience on willow cultivation is in its infantile stage in Romania (Scriba et al. 2012), the work team to be studied was chosen from a limited pool of workers, based on their proven experience in such operations.

In this study, the motor-manual worker felled the stems using a Husqvarna 545 RX brush cutter (Husqvarna AB, Stockholm, Sweden) equipped with a steel saw blade, while the manual assistant used a wooden stick to laterally direct the harvested stems (Fig. 2). Before the study, verbal consent of the workers was obtained during discussions with them and the WSRC's owner. The scope of the study as well as the kind of data to be collected and its intended use was explained to all the participants. Then the workers were instructed to carry on their jobs as usual.

Five devices were used to collect the data needed to evaluate the ergonomics specific to motor-manual felling of WSRC (Fig. 2). To be able to distinguish between different work events and to separate them from the total study time, an Extech ${ }^{\circledR}$ VB 300 motion detection datalogger (Extech Instruments, FLIR Commercial Systems Inc., Nashua, USA) was placed on the brush cutter engine so as to avoid obstructing the usual way of working (Fig. 2). Such instruments are characterized by a small size and a low weight $(20 \mathrm{~g})$ and are designed to collect accurate $( \pm 0.5 \mathrm{~g})$ three-axis acceleration data in the range of $\pm 18 \mathrm{~g}$. They are suitable for monitoring motor-manual operations (Borz et al. 2018), while their sampling rates can be easily manipulated to collect data at less than one second. Exposure to noise was monitored using an Extech ${ }^{\circledR}$ 407760 sound dosimeter datalogger, which was placed near the right ear of the feller (Fig. 2), at a standardized distance of $10 \mathrm{~cm}$ (Poje et al. 2015). To ensure this distance, the device was fixed on the feller's helmet using adhesive tape. While it does not hold the capabilities of a fully professional science-developed dosimeter such as those described, for instance, by Poje et al. (2015) and Poje et al. (2016), respectively, it can collect accurate data on a preset scale (either $\mathrm{dB}(\mathrm{A})$ or $\mathrm{dB}(\mathrm{C})$ ) that can be used in the estimation of most of the ergonomic-assessment noise-related parameters. Similar to the motion detection datalogger, it is characterized by reduced size and weight $(20 \mathrm{~g})$, and simple procedures for setup, data collection and analysis. A Garmin ${ }^{\circledR}$ 62 STC GPS unit (Garmin Ltd., Olathe, USA) was used to collect movement and location data needed to estimate time consumption and to compute part of the performance metrics (Fig. 2). Such consumer-grade devices are able to accurately document the movement and location, which makes them suitable for data collection in motor-manual operations (Talagai et al. 2017, Talagai and Borz 2016). A Polar ${ }^{\circledR}$ V800 (Polar, Finland) device was used to monitor the heart rate of the motormanual feller. It consists of a pericardial strap, which incorporates a sensor able to collect and transmit data via Bluetooth ${ }^{\circledast}$ technology to a smart watch placed on the hand of a person. Such data can be transferred to an online data repository using the FlowSync application developed by Polar ${ }^{\circledR}$, from where it can be exported in several digital formats including MS Excel CSV files.

The choice of dataloggers used in this study was mainly based on the size criterion. To this end, size was considered to be important as the study aimed to simultaneously collect data for all the parameters without burdening the workers with the need to carry substantial weight. Such an approach also helped to avoid interference in carrying out the usual work, which is known to affect study results (Acuna et al. 2012). All of the used devices were setup to collect data at one second intervals. Motion detection, sound dosimeter and heart rate dataloggers were setup using their corresponding purpose-built software, while the setup of the GPS receiver was made using its interface. 
Once all the setups were made, at the beginning of the work day, dataloggers were placed on the feller and they were started simultaneously. When the operations were completed, they were switched off.

During the work day, parts of the operations were randomly sampled and videotaped using a digital camera. A field researcher successively moved forward and videotaped the operations as the work progressed. The resulting files were used for postural assessment, which was implemented for both workers. Using the procedures described above, the operations were observed for a work day in which the team managed to fell all the stems from the designated plot.

\subsection{Data Processing and Analysis}

All of the devices used in this study are capable to export the data as MS Excel files and to label the collected variables with the date and time of collection, features that were used to pair the field data based on such characteristics. For the GPS and acceleration data, the procedures used in this study to process the data were similar to those reported by Borz et al. (2018). They consisted of setting acceleration (A, g) and movement speed $(\mathrm{S}, \mathrm{km} / \mathrm{h})$ thresholds to distinguish between different kinds of work tasks. To manage the data, this study assumed two primitive events that could be recognized using the speed data derived from the GPS collected files: stopped or felling $(S \leq 2 \mathrm{~km} / \mathrm{h}$ ) and waking without actually felling $(\mathrm{S}>2 \mathrm{~km} / \mathrm{h})$. The state of the brush cutter engine was evaluated based on the behavior of acceleration data resulting in two primitive events: engine off $(A \leq 4 \mathrm{~g})$ and engine on $(A>4 \mathrm{~g})$. Following the threshold setting, the GPS and acceleration data were used to derive four final work events: stopped, felling, walking with engine off and walking with engine on. Based on the classification of work events, data characterizing time consumption (s) and physical strain (heart rate, bpm), was attributed, after downloading it from the collectors, to each work event. Then it was used to map the results using QGis software and to analyze it according to the proper procedures.

Time consumption data helped to compute the productive performance of motor-manual felling operations based on the size of operated area and time inputs, as well as to evaluate the time spent on different work tasks. Physical strain of the motor-manual feller was evaluated based on the general approaches used to compute the heart rate reserve (\%HRR). To this end, calculations were made on work events and on the work day using Eq. 1 (Vitalis 1987).

$$
\% H R R_{\mathrm{i}}=\left(H R w_{\mathrm{i}}-H R r\right) \times 100 /(H R \max -H R r)
$$

Where:

$\% H R R_{\mathrm{i}}$ heart rate reserve of the event $\mathrm{i}$ or of the work day

$H R w_{\mathrm{i}} \quad$ working heart rate of the event $\mathrm{i}$ or of the work day, calculated as the average number of beats per minute of the event $i$ or of the work day, bpm

HRmax maximum heart rate calculated using the classical formula: 220 - worker age (42 years in this study) as described by Rodahl (1989)

$\mathrm{HRr}$ resting heart rate calculated as the minimum of a 10 minute rest period prior to starting the work or the minimum value of the HR recorded during the study.

Data characterizing the exposure to noise was downloaded from the datalogger using the dedicated software and it was saved as a MS Excel spreadsheet. Since the exposure to noise is affected by the engine state, the data was analyzed according to the European legislation (European directive 2003/10/EC) and international standards ISO 9612:2009 and ISO 11201:2010 by taking into consideration only the two states of the engine: off and running. The A-weighted equivalent continuous sound pressure level in ABA (LA) as well as the A-weighted noise exposure level, normalized to a nominal 8-h working day $\left(\mathrm{L}_{\mathrm{EX} / \mathrm{sh}}\right)$, were computed for the tasks carried out by the feller. Data characterizing time consumption, acceleration, physical strain and exposure to noise covered about 6.2 hours.

Video data was used to extract the frames to be used in the postural assessment. To this end, each video file was broken into frames at one second sampling rate resulting into a total number of 6053 frames. The Ovako Working posture Analysis System (OWAS), as described by Karhu et al. (1977), was used to evaluate the postural risk index (PRI) using a procedure similar to that described by Calvo (2009), Spinelli et al. (2016) and Zanuttini et al. (2005). The choice of the OWAS system was made due to its capability to cover the whole body, simplicity of use, reliability and comparability of results (Spinelli et al. 2016). The frames that could not be used to evaluate the posture of each body segment were excluded. Each of the remaining frames was analyzed twice and classified in order to compute the Action Category (AC) score that was further used to derive the postural risk index (PRI) for both workers under study based on a detailed analysis of each body segment. Based on the postural data analysis, the data was comparatively plotted and described to enable the comparison between the workers in terms of shares in action categories and in terms of shares of body segment postures in action codes. 


\section{Results and Discussion}

\subsection{Time Consumption and Productive Performance}

The results characterizing the productivity were in line with the general productive performance of motor-manual harvesting operations of WSRC reported by several studies. The area under study $(\mathrm{S}, \mathrm{ha})$ was of 0.35 hectares and it was harvested in about 6.2 hours, meaning that the gross production rate was of approx. $0.07 \mathrm{ha} / \mathrm{h}$. Although the results of this study should be interpreted as preliminary, they were comparable with the results reported by Borz et al. (2018) and Talagai et al. (2017) for similar harvesting systems and with those reported for motor-manual harvesting of WSRCs, in general (Schweier and Becker 2012,
Vanbeveren et al. 2015). Engine working time (Fig. 3) accounted for a share of $68.13 \%$, but only $61.72 \%$ of the total time was evaluated as effective cutting time (Fig. 4). This result was similar to that reported by Borz et al. (2018). The rest was evaluated as walking with engine on. Various kinds of delays accounted for more than $17 \%$.

\subsection{Ergonomics of Motor-manual Felling}

\subsubsection{Heart Rate}

The minimum heart rate $(71 \mathrm{bpm})$ was recorded during the effective working time and not during the time in which the worker was asked to sit in a comfortable position for such determinations. Therefore this value was used in further calculations as the heart rate at rest $(H R r)$. Fig. 5 shows a partition of the field
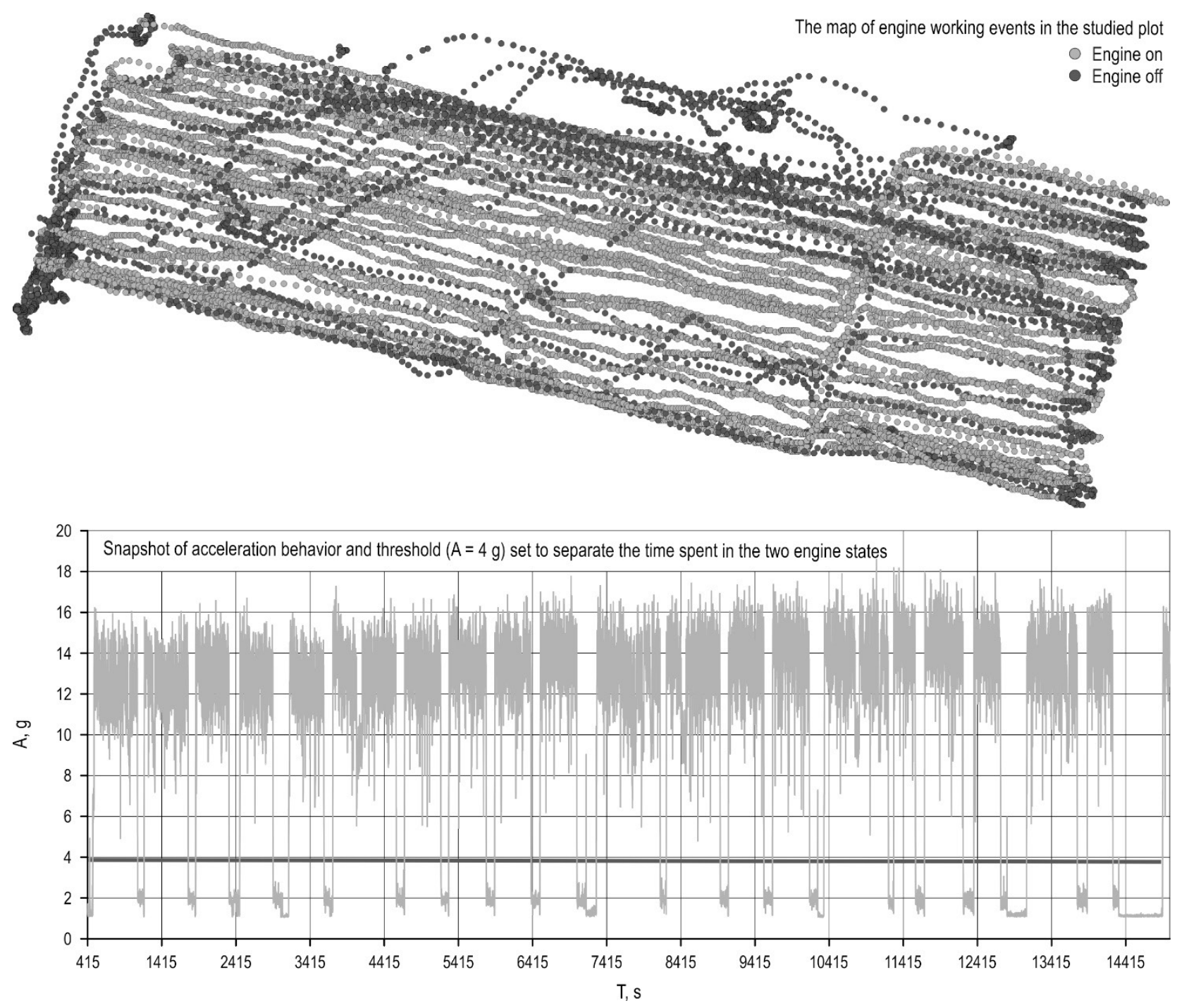

Fig. 3 Engine working time 

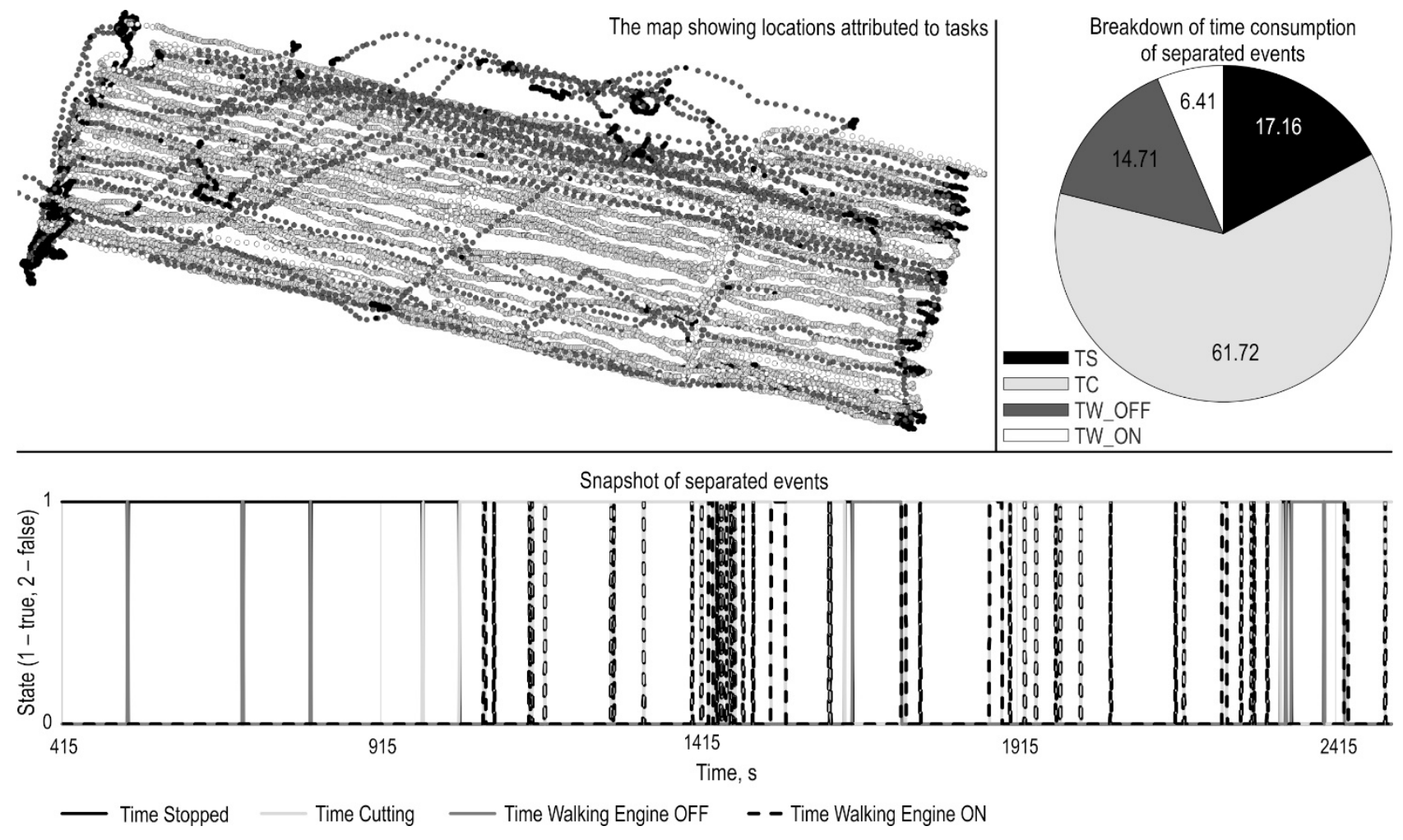

Fig. 4 Estimates of time consumption of work tasks

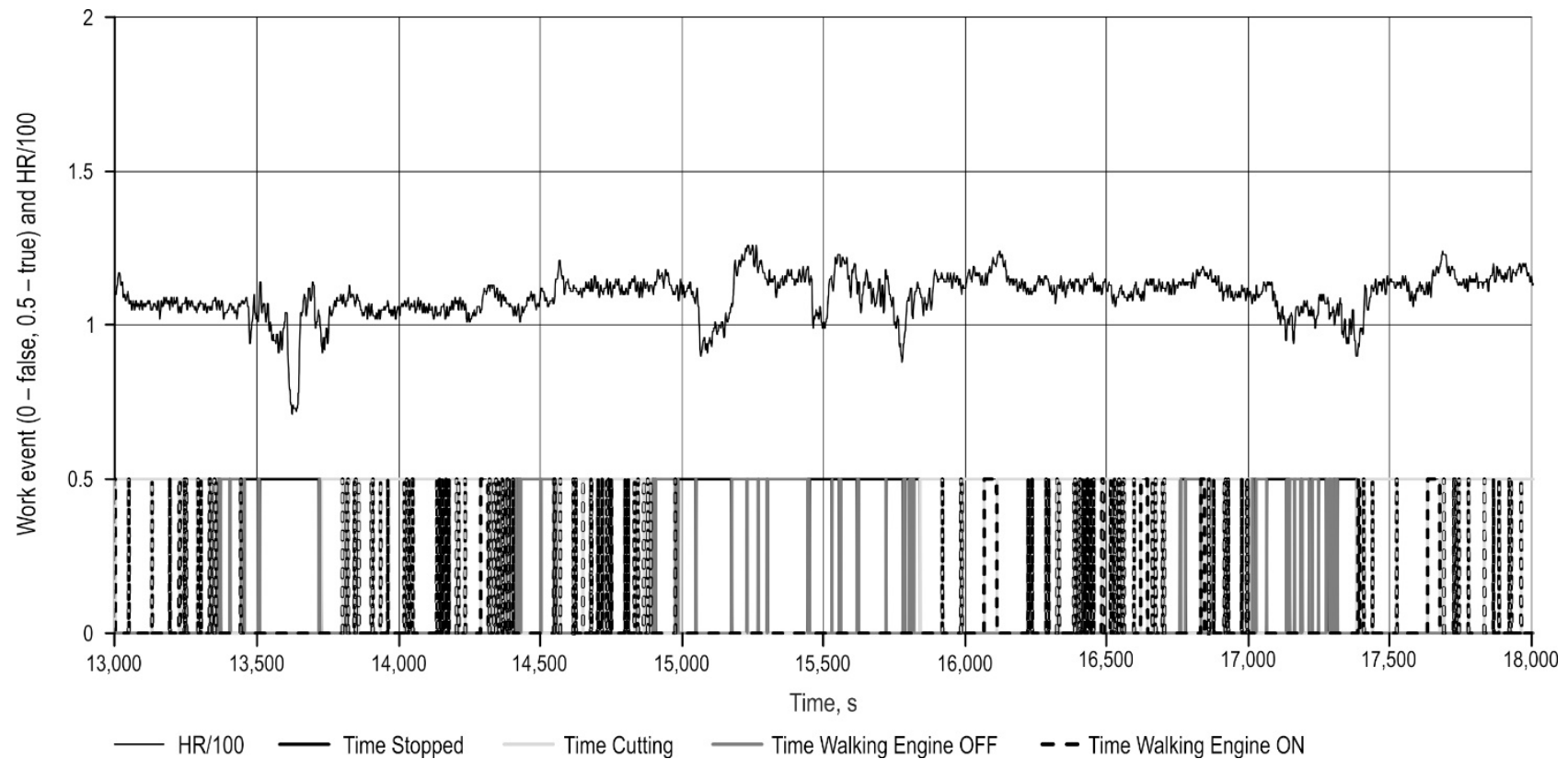

Fig. 5 A snapshot of heart rate plotted against cumulate time and observed work tasks

collected data plotted against the cumulate time and the work events identified during the study. As shown, the time in which the worker was identified as not moving can also be identified in the heart rate behavior. During the events in which the felling team was stopped (Table 1), the physical strain in terms of \%HRR 
Table 1 Cardiovascular load during motor-manual felling tasks of WSRC

\begin{tabular}{|l|c|c|c|c|c|c|c|}
\hline & \multicolumn{7}{|c|}{ Descriptive statistics of heart rate } \\
\hline Work task & Count & Min. & Max. & Average & St.Dev. & HRw/HRr & $\%$ HRR \\
\hline Stopped & 3882 & 71 & 131 & 102.57 & \pm 9.79 & 1.44 & 29.51 \\
\hline Felling & 13962 & 88 & 131 & 109.52 & \pm 5.44 & 1.54 & 36.00 \\
\hline Walking with engine on & 3328 & 84 & 159 & 108.99 & \pm 6.64 & 1.54 & 35.50 \\
\hline Walking with engine off & 1449 & 90 & 123 & 111.02 & \pm 5.57 & 1.56 & 37.40 \\
\hline Total & 22621 & 71 & 159 & 108.35 & \pm 7.09 & 1.53 & 34.90 \\
\hline
\end{tabular}

was evaluated at almost $30 \%$ for the feller, while in the events in which the work tasks involved movement, the \%HRR was in the range of $35.50-37.40 \%$. Nevertheless, there were situations (Fig. 6) in which the heart rate reserve exceeded well the permissible value (in some cases more than $80 \%$ ). Such events accounted for almost $23 \%$ of the total study time. Compared to the effort undertaken by brush cutters in traditional forestry operations (Toupin et al. 2007), cardiovascular load in this study was significantly lower (34.90\%) indicating lower physical effort in motor-manual felling of WSRC when using similar equipment. Nevertheless, it exceeded the threshold of $24.5 \%$ proposed by Wu and Wang (2002) as an acceptable level for an 8-h work day but it was less than the $40 \%$ - a permissible value as described by Potočnik and Poje (2017).

In addition, motor-manual felling using brush cutters involves a significant use of dynamic work of the upper limbs. According to Velásquez et al. (2015), the maximum acceptable working time is even smaller when dynamic work is carried out using the upper limbs. However, compared to traditional forest operations, the results reported herein indicate significantly smaller cardiovascular loads of the motor-manual feller. For instance, cardiovascular loads of regular harvesting operations using chainsaws may exceed the permitted value of $40 \%$ (Cheța et al. 2018, Potočnik and Poje 2017), while in the cable work heart rate reserve seems to vary in a wide range (Kirk and Sullman 2001, Ottaviani et al. 2011, Magagnotti and Spinelli 2012, Stampfer et al. 2010). Nevertheless, the approach of combining heart rate with GPS collected data may be of help in understanding the factors that contribute to the physical effort as well as their location of occurrence, as shown for instance in Fig 6.

\subsubsection{Exposure to Noise}

Table 2 shows the descriptive statistics of the time spent with engine off and on, respectively. As shown,

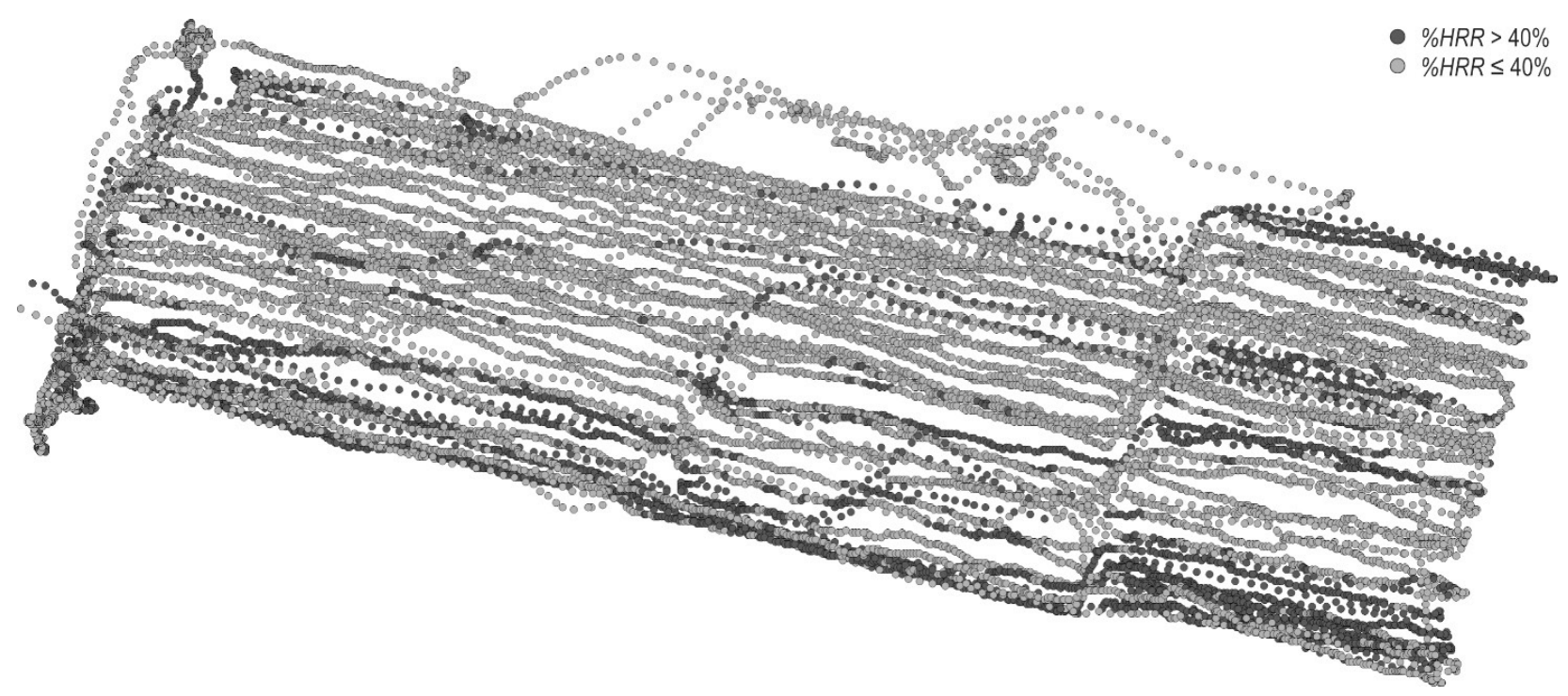

Fig. 6 A map of heart rate reserve 
Table 2 Exposure to noise in motor-manual felling of WSRC

\begin{tabular}{|l|c|c|c|c|}
\hline & \multicolumn{4}{|c|}{ Exposure to noise } \\
\hline Work task & Time & $\begin{array}{c}\text { \% of total } \\
\text { time }\end{array}$ & LA & $L_{E X, 8 \mathrm{~h}}$ \\
\hline $\begin{array}{l}\text { Stopped \& walking } \\
\text { with engine off }\end{array}$ & 7212 & 31.9 & 63.53 & 57.51 \\
\hline $\begin{array}{l}\text { Cutting \& walking } \\
\text { with engine on }\end{array}$ & 15409 & 68.1 & 97.90 & 95.19 \\
\hline Total & 22621 & 100.0 & 96.24 & 95.19 \\
\hline
\end{tabular}

the engine was running for more than $68 \%$ of the study time. Both, the A-weighted equivalent continuous sound pressure level (LA) and the A-weighted noise exposure level normalized to a nominal 8-h working day $\left(\mathrm{L}_{\mathrm{Ex}, 8 \mathrm{~h}}\right)$ exceeded the exposure limit value $(87 \mathrm{dBA})$ prescribed by the European legislation. In such circumstances, the use of protective equipment is mandatory. It is important to mention here that the observation time in this study was less than 8 hours, and the engine utilization rate was $68 \%$. Therefore, the results reported herein are purely descriptive and further studies should clarify how the redistribution of working time would affect the exposure to noise, as a higher utilization rate of the engine could increase the noise level (Poje et al. 2015). In any case, wearing hearing protectors would reduce the exposure to noise to an acceptable level. For instance, ear plugs can provide a sound attenuation of between $15 \mathrm{dBA}$ for low frequency sounds and $35 \mathrm{dBA}$ for higher frequencies (Helander 2006). At the same time, modern helmets can provide a sound attenuation of $26 \mathrm{dBA}$. While the exposure to noise was only tested for the motor-manual feller, protective equipment would also be required for the manual assistant given the short distance from his ear to the noise source.

\subsubsection{Postural Assessment}

Frame refinement resulted in 5825 and 5779 valid frames that were analyzed for the manual assistant and motor-manual feller, respectively. The valid frames covered about 1.62 and 1.61 hours of study for the manual assistant and motor-manual feller, respectively, accounting for more than $25 \%$ of the total study time.

Table 3 shows a breakdown of the back, arms, legs and force exertion codes attributed to two workers in the postural analysis. As shown, in motor-manual felling of WSRCs, when using brush cutters, the main differences were those specific to the back posture, which was assessed as being less comfortable for the manual assistant who was identified more frequently with his back bent and twisted or bent forward and sideways (to the right in this study) - almost $90 \%$ of the sampled time. Obviously, this was a consequence of the organizational layout of the operations in which the location of the assistant was recorded predominantly to the left-backwards of the motor-manual feller. Compared to the manual assistant, the motormanual feller was found with such awkward postures of the back only in $21 \%$ of the sampled time. In his case, the predominant posture of the back was that specific to the second category - bent forward - which accounted for a share of almost $70 \%$ of the sampled

Table 3 Shares of codes attributed to the back, arms, legs and force exertion in the postural analysis

\begin{tabular}{|c|c|c|c|c|c|c|c|c|}
\hline \multirow{2}{*}{ Code } & \multicolumn{9}{|c|}{ Shares of body segments postures on postural codes, $\%$} & \multicolumn{3}{c|}{ Legs } & \multicolumn{2}{c|}{ Arms } & \multicolumn{2}{c|}{ Force exertion } \\
\cline { 2 - 11 } & Feller & Assistant & Feller & Assistant & Feller & Assistant & Feller & Assistant \\
\hline 1 & 2.94 & 0.36 & 99.91 & 99.83 & 0.00 & 0.05 & 100.00 & 100.00 \\
\hline 2 & 69.44 & 2.73 & 0.09 & 0.17 & 0.09 & 0.10 & 0.00 & 0.00 \\
\hline 3 & 6.23 & 7.61 & 0.00 & 0.00 & 0.03 & 0.02 & 0.00 & 0.00 \\
\hline 4 & 21.39 & 89.29 & NA & NA & 0.17 & 0.00 & NA & NA \\
\hline 5 & NA & NA & NA & NA & 0.02 & 0.00 & NA & NA \\
\hline 6 & NA & NA & NA & NA & 0.00 & 0.00 & NA & NA \\
\hline 7 & NA & NA & NA & NA & 99.69 & 99.83 & NA & NA \\
\hline Total & 100.00 & 100.00 & 100.00 & 100.00 & 100.00 & 100.00 & 100.00 & 100.00 \\
\hline
\end{tabular}

Note: NA - not applicable 


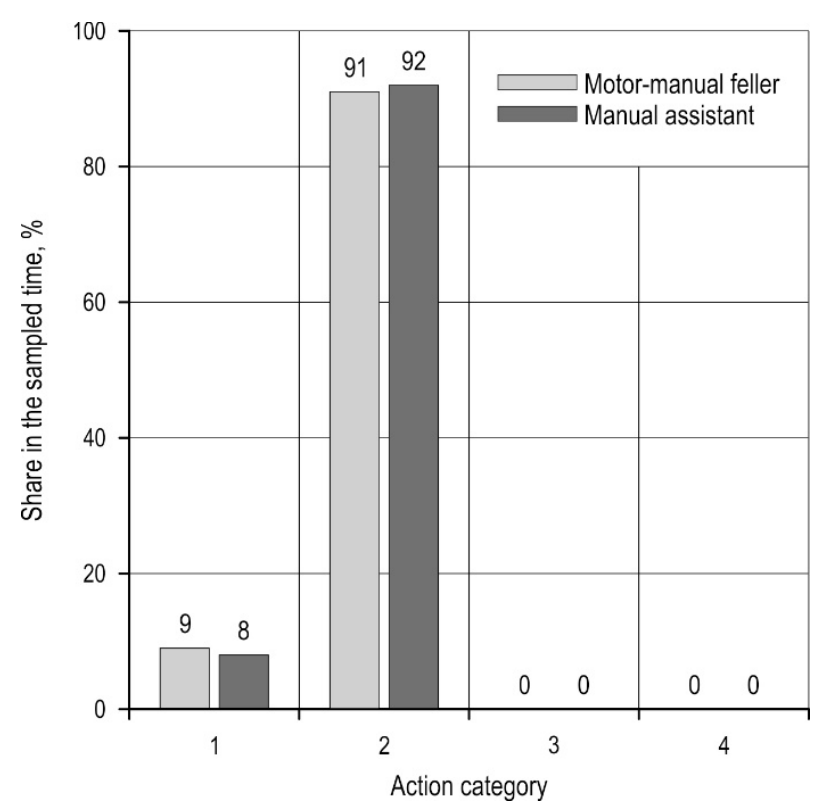

Fig. 7 Share of evaluated frames in ergonomic action categories

time. In both cases, the posture of arms was assessed as being comfortable (almost $100 \%$ of the evaluated postures in the first category - both arms located below the shoulder level), while the legs were identified as walking or moving most of the sampled time (almost $100 \%$ for both cases).

In these conditions, more than $90 \%$ of the body postures of both workers were classified as action category 2 (AC2), as shown in Fig. 7. Consequently, the postural risk indexes (PRIs) were rather similar: 191.11 in the case of motor-manual feller and 192.02 in the case of manual assistant. According to the OWAS system, such results advocate for corrective measures to be taken in the near future. However, one should take into account that the studied workers were hired on a daily basis, which means that they also perform other agricultural jobs during the year, while willow harvesting takes place only in short, late-winter/earlyspring periods. Therefore, the postural indexes calculated in this study only cover WSRC felling activities that are much smaller compared, for instance, to similar motor-manual operations such as those of regular forestry work (Calvo 2009, Cheța et al. 2018, Zanuttini et al. 2005). Nevertheless, studies on other kinds of wood procurement activities such as wood splitting and wood debarking have reported smaller postural risk indexes compared to those reported in this study (Spinelli et al. 2018, Spinelli et al. 2016).

On the other hand, the greatest concerns of using brush cutters are those related to the safety of workers within the operation zone. Equipment manufacturers recommend a safety distance of at least $15 \mathrm{~m}$ for other persons working in the area when using brush cutters, but even maintaining a safety distance of $15 \mathrm{~m}$ cannot exclude the potential danger. That is why the coworkers located in the danger area should wear eye protection equipment. Given the risks of exposure to noise, professional helmets providing eye and ear protection should be worn in motor-manual felling of WSRCs.

\section{Conclusions}

This study aimed to evaluate some of the ergonomic conditions in motor-manual felling of WSRCs. Since the ergonomic studies usually also describe the work tasks, in this study we used an automated procedure to collect data on time consumption, productivity, physical strain and exposure to noise, which were complemented by an assessment of postural risk index observed in a traditional fashion. Given its limited temporal extent, this study should be interpreted as a preliminary integrative attempt to evaluate the ergonomic conditions of WSRCs motor-manual felling operations. As such, a validation of these preliminary results should be undertaken by conducting similar studies on longer terms, attempts that may benefit from using procedures of data collection as those described herein, which enable the possibility to account for operational variability, exclude the researcher interference in carrying out the usual work, and have a lot of potential in reducing the costs caused by the study implementation. Probably the biggest benefit of these procedures is that they enable a cheap integrated data collection, which is very often difficult to implement. They are also easy to use and do not contribute by supplementary burdens in terms of weight to be carried by the observed workers. For instance, combining acceleration with GPS data allows for an accurate separation of work tasks, while combining the heart rate with GPS data may allow for identification of factors that contribute to the physical strain as well as their location of occurrence.

The results of this study point out that the time consumption and productivity of motor-manual felling of WSRCs were comparable to other field tests, with small variations that were caused by the operational layout in this study. While not exceeding, in average, the permitted value of the cardiovascular load, motor-manual felling of WSRC tends to be a moderate to heavy work, with some cases in which the heart rate reserve exceeded $40 \%$ ( $23 \%$ of the study time). Also, there were some short events in which it exceeded even $80 \%$. Among the greatest concerns in this kind of operations are the exposure to noise and 
work safety because the permitted values of noise exposure were exceeded in this field test. This situation, as well as safety reasons, advocate for the use of professional protective equipment able to provide ear and eye safety. While not being exposed to great postural risks, the workers operating in motor-manual felling of WSRCs make a substantial use of dynamic work with the upper limbs. Therefore, further studies should also evaluate how this kind of work may affect the health of operators.

\section{Acknowledgements}

This study was supported by the Department of Forest Engineering, Forest Management Planning and Terrestrial Measurements of the Faculty of Silviculture and Forest Engineering, Transilvania University of Braşov and by the Doctoral School of the Transilvania University of Braşov. The authors are grateful for the logistics and material support provided. Also, the authors would like to thank Mr. Eng. Arpad Domokos and the workers taken into study for agreeing to carry on the study. The authors would like to thank the anonymous reviewers for their valuable comments and suggestions that helped in improving this paper.

\section{References}

Acuna, M., Bigot, M., Guerra, S., Hartsough, B., Kanzian, C., Kärhä, K., Lindroos, O., Magagnotti, N., Roux, S., Spinelli, R., Talbot, B., Tolosana, E., Zormaier, F., 2012: Good practice guidelines for biomass production studies. CNR IVALSA Sesto Fiorentino, $51 \mathrm{p}$.

Borz, S.A., Talagai, N., Cheța, M., Gavilanes Montoya, A.V., Castillo Vizuete, D.D., 2018: Automating data collection in motor-manual time and motion studies implemented in a willow short rotation coppice. Bioresources 13(2): 3236-3249.

Buchholz, T., Volk, T.A., 2011: Improving the profitability of willow crops - Identifying opportunities with a crop budget model. Bioenergy Research 4(2): 85-95. https://doi. org/10.1007/s12155-010-9103-5

Burger, F.J., 2010: Cultivation and Life Cycle Assessment of Short Rotation Coppice, PhD Dissertation, Technical University of Munich, Munich, Germany, $180 \mathrm{p}$.

Calvo, A., 2009: Musculoskeletal disorders (MSD) risks in forestry: a case study to propose an analysis method. Agricultural Engineering International 11: 1-9.

Cheța, M., Marcu, M.V., Borz, S.A., 2018: Workload, exposure to noise, and risk of musculoskeletal disorders: a case study of motor-manual tree felling and processing in poplar clear cuts. Forests 9(6): 300. https://doi.org/10.3390/\$9060300

Corella Justavino, F., Jimenez Ramirez, R., Meza Perez, N., Borz, S.A., 2015: The use of OWAS in forest operations postural assessment: advantages and limitations. Bulletin of the
Transilvania University of Braşov, Series II: Forestry - Wood Industry - Agricultural Food Engineering 57(2): 7-16.

Eisenbies, M.H., Volk, T.A., Posselius, J., Foster, C., Shi, S., Karapetyan, S., 2014: Evaluation of a single-pass, cut and chip harvest system on commercial-scale, short rotation shrub willow biomass crops. Bioenergy Research 7(4): 1506-1518. https://doi.org/10.1007/s12155-014-9482-0

El Kasmioui, O., Ceulemans, R., 2013: Financial analysis of the cultivation of short rotation woody crops for bioenergy in Belgium: barriers and opportunities. Bioenergy Research 6(1): 336-350. https://doi.org/10.1007/s12155-012-9262-7

Fonseca, A., Aghazadeh, F., de Hoop, C., Ikuma, L., Al-Qaisi, A., 2015: Effect of noise emitted by forestry equipment on workers' hearing capacity. International Journal of Industrial Ergonomics 46: 105-112. https://doi.org/10.1016/j.ergon.2014.05.001

Guidi, W., Pitre, F.E., Labercque, M., 2013: Short rotation coppice of willows for the production of biomass in Eastern Canada. In: Biomass Now - Sustainable Growth and Use, Matovic M.D. (ed.), INTECH, 421-448. https://doi.org/ $10.5772 / 51111$

Helander, M., 2006: A guide to human factors and ergonomics. Second Edition. CRC Press Taylor \& Francis Group, New York, 408 p. https://doi.org/10.1177/106480460701500308.

Helby, P., Rosenqvist, H., Roos, A., 2006: Retreat from Salix - Swedish experience with energy crops in the 1990s. Biomass and Bioenergy 30(5): 422-427. https://doi.org/10.1016/j. biombioe.2005.12.002

Karhu, O., Kansi, P., Kuorinka, I., 1977: Correcting working postures in industry: a practical method for analysis. Applied Ergonomics 8(4): 199-201.

Kirk, P.M., Sullman, M.J.M., 2001: Heart rate strain in cable hauler choker setters in New Zealand logging operations. Applied Ergonomics 32: 389-398. https://doi.org/10.1016/ S0003-6870(01)00003-5

Magagnotti, N., Spinelli, R., 2012: Replacing steel cable with synthetic rope to reduce operator workload during log winching operations. Small Scale Forestry 11: 223-236. https://doi.org/10.1007/s11842-011-9180-0

Ottaviani, G., Talbot, B., Nitteberg, M., Stampfer, K., 2011: Workload benefits of using a synthetic rope strawline in cable yarder rigging in Norway. Croatian Journal of Forest Engineering 32(2): 561-569.

Pecenka, R., Ehlert, D., Lenz, H., 2014: Efficient harvest lines for Short Rotation Coppices (SRC) in Agriculture and Agroforestry. Agronomy Research 12(1): 151-160.

Poje, A., Potočnik, I., Danilović, M., Antonić, S., 2016: A case study of the impact of skidding distance on tractor operator exposure to noise. Baltic Forestry 22(2): 357-364.

Poje, A., Spinelli, R., Magagnotti, N., Mihelić, M., 2015: Exposure to noise in wood chipping operations under conditions of agro-forestry. International Journal of Industrial Ergonomics 50: 151-157. https://doi.org/10.1016/j.ergon.2015.08.006 
Potočnik, I., Poje, A., 2017: Forestry ergonomics and occupational safety in high ranking scientific journals from 20052016. Croatian Journal of Forest Engineering 38(2): 291-310.

Rodahl, K., 1989: The physiology of work. Taylor and Francis, London, 269 p.

Schweier, J., Becker, G., 2012: Motor manual harvest of short rotation coppice in South-West Germany. Allgemeine Forst und Jagdzeitung 183(7-8): 159-167.

Scriba, C., Borz, S.A., Talagai, N., 2014: Estimating dry mass and bark proportion in one-year shoots yielded by one-year Salix viminalis L. plantations in Central Romania. Revista Pădurilor 129(3-4): 57-66.

Spinelli, R., Aminti, G., Magagnotti, N., De Francesco, F., 2018: Postural risk assessment of small-scale debarkers for wooden post production. Forests 9(3): 111.

Spinelli, R., Aminti, G., de Francesco, F., 2017: Postural risk assessment of mechanized firewood processing. Ergonomics 60(3): 375-383. https://doi.org/10.3390/\$9030111

Spinelli, R., Schweier, J., de Francesco, F., 2012: Harvesting techniques for non-industrial biomass plantations. Biosystems Engineering 113(4): 319-324. https://doi.org/10.1016/j. biosystemseng.2012.09.008

Stampfer, K., Leitner, T., Visser, R., 2010: Efficiency and ergonomic benefits of using radio controlled chokers in cable yarding. Croatian Journal of Forest Engineering 31(1): 1-9.

Talagai, N., Borz S.A., Ignea, G., 2017: Performance of brush cutters in felling operations of willow short rotation coppice. Bioresources 12(2): 3560-3569.

Talagai, N., Borz S.A., 2016: Concepts for data collection automation with applicability in the evaluation of productive performance of willow short rotation coppice. Revista Pădurilor 131(3-4): 78-94.

Taoda, K., Watanabe, S., Nishiyama, K., Fukuchi, Y., Miyakita, T., 1987: Survey of noise exposure level on national forestry workers. Department of Preventive Medicine, Shiga University of Medical Science, Otsu, Japan.
Tunay, M., Melemez, K., 2008: Noise induced hearing loss of forest workers in Turkey. Pakistan Journal of Biology Science 11(17): 2144-2148. https://doi.org/10.3923/pjbs.2008.2144.2148

Toupin, D., LeBel, L., Dubeau, D., Imbeau, D., Biuthillier, L., 2007: Measuring the productivity and physical workload of brushcutters within the context of a production-based pay system. Forest Policy and Economics 9: 1046-1055. https:// doi.org/10.1016/j.forpol.2006.10.001

Vanbeveren, S.P.P., De Francesco, F., Ceulemans, R., Spinelli, R., 2018: Productivity of mechanized whip harvesting with the Stemster MkIII in a short-rotation coppice established on farmland. Biomass and Bioenergy 108: 323-329. https://doi. org/10.1016/j.biombioe.2017.11.024

Vanbeveren, S.P.P., Schweier, J., Berhongaray, G., Ceulemans, R., 2015: Operational short rotation woody crop plantations: manual or mechanized harvesting? Biomass and Bioenergy 72: 8-18. https://doi.org/10.1016/j.biombioe.2014.11.019

Velásquez, J., Briceno, L., Ortiz, L., Solarte, S., Agredo, R., 2015: Maximum acceptable work time for the upper limbs task and lower limbs task. Procedia Manufacturing 3:45844590. https://doi.org/10.1016/j.promfg.2015.07.535

Vitalis, A., 1987: The use of heart rate as the main predictor of the cost of work. In: Proceedings of the inaugural conference of the NZ ergonomics society. Aukland, 168-181.

Wu, H.C., Wang, M.J.J., 2002: Relationship between maximum acceptable work time and physical workload. Ergonomics 45(4): 280-289. https://doi.org/10.1080/00140130210123499

Zanuttini, R., Cielo, P., Poncino, D., 2005: The OWAS Method. Preliminary results for the evaluation of the risk of workrelated musculo-skeletal disorders (WMSD) in the forestry sector in Italy. Forest@ - Rivista Di Selvicoltura Ed Ecologia Forestale 2: 242-255. https://doi.org/10.3832/efor0294-0020242

The European Parliament/Council, 2003: Directive 2003/10/ EC on the minimum health and safety requirements regarding the exposure of workers to the risks arising from physical agents (noise) (Seventeenth individual Directive within the meaning of Article 16(1) of Directive 89/391/EEC), 7 p.

(C) 2018 by the authors. Submitted for possible open access publication under the terms and conditions of the Creative Commons Attribution (CC BY) license (http://creativecommons.org/licenses/by/4.0/). 
Authors' addresses:

Prof. Stelian Alexandru Borz, PhD* e-mail: stelian.borz@unitbv.ro Nicolae Talagai, MSc e-mail: nicu_tin@yahoo.com Marius Cheța, MSc e-mail: chetza.marius@yahoo.com Diana Chiriloiu e-mail: diana.chiriloiu@student.unitbv.ro Alex Vinicio Gavilanes Montoya, MSc e-mail: alexgavilanes19871@gmail.com Danny Daniel Castillo Vizuete, MSc e-mail: dannycv85@gmail.com Assist. prof. Marina Viorela Marcu, PhD e-mail: viorela.marcu@unitbv.ro Transilvania University of Braşov Faculty of Silviculture and Forest Engineering Department of Forest Engineering Forest Management Planning and Terrestrial Measurements Şirul Beethoven, No. 1 500123 Braşov

* Corresponding author 